\title{
Genotype $\times$ Environment interactions in Pinus pinaster at age 10 in a multi-environment trial in Portugal: a maximum likelihood approach
}

\author{
Isabel CORREIA ${ }^{1 *}$, Ricardo AlíA ${ }^{2}$, Weikai YAN ${ }^{3}$, Teresa DAVID ${ }^{4}$, Alexandre AgUiAR $^{4}$, \\ Maria Helena ALMEIDA ${ }^{1}$ \\ ${ }^{1}$ Instituto Superior de Agronomia, Tapada da Ajuda, 1349-017 Lisboa, Portugal \\ ${ }^{2}$ Instituto Nacional de Investigación y Tecnologia Agraria y Alimentaria. Carretera de la Coruña Km 7.5, 28040 Madrid, Spain \\ ${ }^{3}$ Agriculture and Agri-Food Canada, 3010 Neatby Building, 960 Carling Ave., Ottawa, ON, K1A 0C6, Canada \\ ${ }^{4}$ Instituto Nacional dos Recursos Biológicos, I.P., Quinta do Marquês, 2780-159 Oeiras, Portugal
}

(Received 28 May 2009; accepted 2 December 2009)

Keywords:

maritime pine /

adaptive variation /

provenance trial /

likelihood-based analysis /

GGE biplot

\begin{abstract}
- To study adaptive variation and genotype x environment interactions (GE) of 30 populations from Portugal, Spain, France and Australia, we evaluated total height, diameter, stem form and survival in a multi-environment provenance trial in Portugal, $10 \mathrm{y}$ after plantation, using the restricted maximum likelihood (REML) approach.

- Significant differentiation was found among populations and also among seedlots from Portugal, populations from different altitude classes and from different provenance regions. Seed orchards showed significantly better growth and stem form. GE interaction was significant for all traits which indicates the existence of differences on phenotypic plasticity among populations, and displayed a pattern that could be related to general or specific adaptation of populations, and/or to humanmediated germplasm transfer.

- Seed orchards, and the Monção and Leiria populations showed generally better growth and stem form, and some high altitude populations ranked higher in growth or survival (Bragança, S.Pedro do Sul, Manteigas-Pma30) at the high-altitude Montalegre site. There was a lack of genetic uniformity among populations of the same provenance region.

- Tentative recommendations are made for afforestation, breeding and conservation.
\end{abstract}

\section{INTRODUCTION}

Pinus pinaster has a wide fragmented natural distribution, extending over the western Mediterranean and European Atlantic coast, and is also extensively planted outside this range. Maritime pine is highly appreciated for the economical value of its products and for its ecological role in the protection of soil and water resources, carbon sequestration and biodiversity.

Several countries promoted breeding programs for this species, where provenance trials play an important role in evaluating intraspecific variability. Provenance trials are of fundamental importance in evaluating the adaptive capacities of provenances and patterns of genotype $\times$ environment (GE) interaction, guiding allocation of resources for afforestation, improvement and conservation programs at a relatively low cost. Provenance tests conducted in France (Danjon, 1994),

* Corresponding author: esteves.ic@gmail.com
Spain (Alía et al., 1995), Morocco (Destremeau et al., 1976), Greece (Matziris, 1982), Turkey (Simsek et al., 1985) and Australia (Hopkins and Butcher, 1993) report significant variations in morphologic and adaptive traits throughout the species range, and altitude is an important factor contributing to the interactions (Alía et al, 1997). However, more information is needed on the adaptive variation of provenances in the southwestern Atlantic frontier of Europe. According to international guidelines, conservation measures have been recommended (Alía and Martin, 2003) and provenance regions have been recently delimited for this species in some countries, based on knowledge of the adaptive variation (González-Martínez et al., 2004).

Genetic variability of $P$. pinaster is partly explained by natural selection for drought adaptation and by genetic drift, resulting from population fragmentation due to the pressure of natural or human factors (González-Martínez et al., 2002; Ribeiro et al., 2001). At the species range, variability of growth and stem form is weakly related to the structure found using 
different molecular markers (González-Martínez et al., 2002; 2004), showing 3 main groups: Western (Atlantic), Eastern (Mediterranean) and Moroccan. At present, new insights on the association of drought stress candidate genes to local adaptation patterns are revealing different groups (Eveno et al., 2008).

Overall, when water availability or minimum temperatures are not limitative, mesic Atlantic provenances display higher aboveground growth than Mediterranean and Moroccan provenances (Nguyen-Queyrens et al., 1998), but the latter exhibit higher drought tolerance (Guyon and Kremer, 1982). A high level of phenotypic plasticity for growth and drought tolerance has been reported in several studies (Chambel, 2007; Hopkins and Butcher, 1993; Zas et al., 2004), with Atlantic provenances displaying lower survival under severe water deficits (Alía et al., 1995) or frost stress (Hopkins and Butcher, 1993). Differences in stem form have also been found among populations, mainly explained by differences in competition for light and resistance to snow and wind, with highland populations displaying a better form (González-Martínez et al., 2002; Sierra de Grado et al., 1997).

Traditionally, analysis of multi-environment trials (MET) has relied on analysis of variance and linear regression techniques. However, these methods are less effective in capturing GE patterns than multivariate techniques (see review in Crossa, 1990). There have been two major developments in this type of statistical analysis. One is the maximum likelihood based random effect estimation; the other is the biplot display of two-way tables. Least-Squares adjustment has been widely used but, in a mixed model frame, the restricted maximum likelihood (REML) produces more reliable estimators, especially with unbalanced data. In a mixed model context, variance heterogeneity can be modeled and more precise predictions (best linear unbiased predictions, BLUP) can be obtained for random effects (Piepho et al., 2008). This methodology has been successfully used in forest MET, providing more accurate genetic parameter estimates (Costa e Silva et al., 2006).

Yan et al. (2000) proposed a graphic display based on the principal component biplot described by Gabriel (1971), congregating the two important effects in selection, the main effect of genetic entities $(\mathrm{G})$ and of GE interaction from MET data: the GGE biplot. This representation allows direct visualization of the performance and stability of the genetic entries and their relationship with the test sites. This methodology is extensively described in several studies and has been successfully used in many agronomic trials (Yan et al., 2000, 2007).

The present study reports on results from a likelihoodbased analysis of growth, form and survival, at age 10 , of a $P$. pinaster provenance test at 5 sites in Portugal. The primary objective was to investigate adaptive variation of 30 populations from Portugal, Spain, France and Australia, and to evaluate GE interactions. The specific objectives were (i) to evaluate populations' performances across trials and analyse GE interaction patterns, assessing the influence of altitude and provenance region of origin (ii) to evaluate populations' performances and estimate population heritabilities in each trial site, and (iii) to identify genetic material suitable for afforestation, improvement programs and conservation strategies.

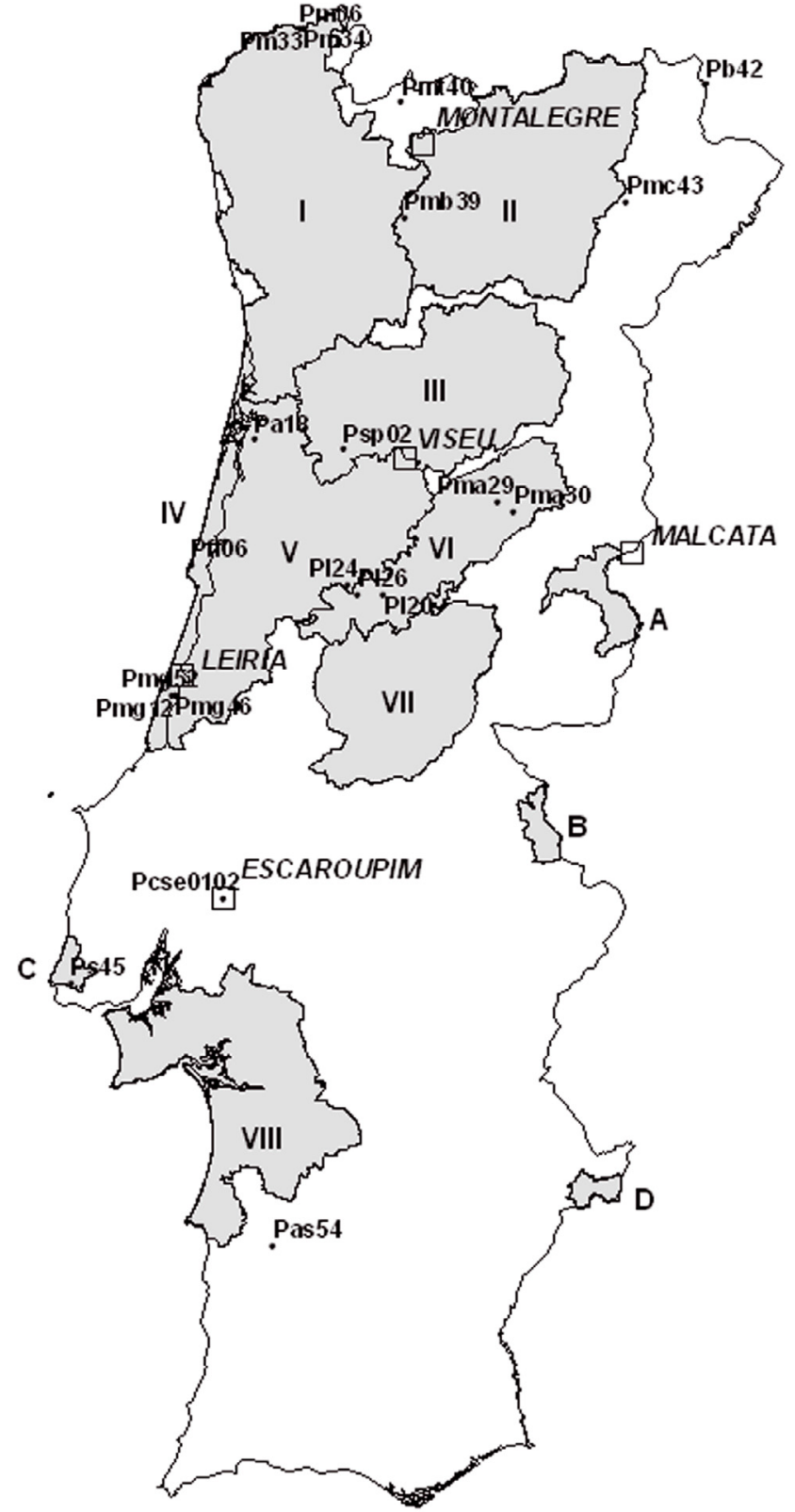

Figure 1. Portuguese populations (22) represented in the trial $\left(^{*}\right)$, experimental fields ( $\square$ ) and provenance regions delimited by the Portuguese Forestry Services (shaded areas; A, B, C, D, are restricted provenance areas).

\section{MATERIAL AND METHODS}

\subsection{Experimental design}

Thirty $P$. pinaster populations and seed orchards seedlots were sampled in this study (30 trees per population, interspaced at least $30 \mathrm{~m}$ ): 22 from Portugal, 2 from Spain, 3 from France and 3 from Australia (Fig. 1, Supplementary material available online only at www.afs-journal.org, Tab. SI). Sampling of populations from the natural range included 21 
Table I. Comparative characteristics of the test sites. Regions of provenance, T, P and Emberger's pluviothermal index Q3 as in Table SI.

\begin{tabular}{|c|c|c|c|c|c|c|}
\hline Test sites & $\begin{array}{l}\text { Altitude } \\
\text { (m) }\end{array}$ & $\begin{array}{c}\text { Region of } \\
\text { provenance } \\
\text { (Portugal) }\end{array}$ & Soil type & $\begin{array}{c}\mathrm{T} \\
\left({ }^{\circ} \mathrm{C}\right)\end{array}$ & $\begin{array}{c}\mathrm{P} \\
(\mathrm{mm})\end{array}$ & Q3 \\
\hline Escaroupim & 10 & - & $\begin{array}{l}\text { Dystric Regosols } \\
\text { (quartz sand deposits } \\
\text { from fluvial origin) }\end{array}$ & 15.3 & 577.6 & 82.9 Subhumid \\
\hline Leiria & 30 & IV & $\begin{array}{l}\text { Spodic Podzols (from sand } \\
\text { dunes of maritime origin) }\end{array}$ & 14.7 & 806.4 & 140.4 Humid \\
\hline Malcata & 800 & - & Humic cambisoils on granite & 15.7 & 780.7 & 98.4 Subhumid \\
\hline Montalegre & 1000 & II & Humic cambisoils on shale & 9.9 & 1487.0 & 220.8 Hyperhumid \\
\hline Viseu & 600 & $\mathrm{~V}$ & Dystric cambisoils & 13.4 & 1200.2 & 153.6 Humid \\
\hline
\end{tabular}

phenotypically selected stands from Portugal along a climate and altitude gradient, ranging from $10 \mathrm{~m}$ to $900 \mathrm{~m}$ asl; 2 populations from Spain (Galicia and Cuenca) and 2 from France (Landes and Corsica). Twenty three populations (21 from Portugal; 1 from Galicia, Spain; 1 from Landes, France) belong to the "western" genetic group, and 2 (Corsica, France; Cuenca, Spain) belong to the "eastern" group, according to GonzálezMartínez et al. (2004). Five clonal seed orchards (sometimes referred to as populations for exposition purposes) with different degrees of breeding were also sampled: Landps62 from France; Pcse0102 (open pollinated crosses of phenotypically selected Leiria's plus trees from Portugal, Fernandes et al., 2008); Sn7901, Sn5063 and D1097 (seed orchards established from crosses between genotypes selected in Leiria, Australia, New Zealand and South Africa) from Australia.

A multi-site provenance test was established in 1993 in Portugal in 5 sites covering a geographic area extending from $39^{\circ}$ $05^{\prime} \mathrm{N}$ to $41^{\circ} 40^{\prime} \mathrm{N}$ in latitude, $6^{\circ} 50^{\prime} \mathrm{W}$ to $8^{\circ} 55^{\prime} \mathrm{W}$ in longitude and ranging from $10 \mathrm{~m}$ to $1000 \mathrm{~m}$ in altitude (Fig. 1, Tab. I). All populations are represented in all the sites. A randomized complete block (RCB) design was used and 2 to 8 replicates were evaluated in each site, as some were lost due to forest fires or human action. Each of the 30 populations is represented in each replicate by 30 tree-plots spaced by $2 \mathrm{~m} \times 3 \mathrm{~m}$ and arranged in square plots. The climatic conditions of origin of the populations and of the test sites were characterized by the annual mean temperature $\left(T,{ }^{\circ} \mathrm{C}\right)$, the annual cumulative precipitation $(P, \mathrm{~mm})$ and the Emberger pluviothermal index, a ratio between rainfall and thermal continentality that takes into consideration the climatic variables for plant activity. This index was estimated as $Q 3=3.43 P /(M-m)$, where $M=$ mean maximal temperature for the hottest month and $m=$ mean minimal temperature for the coldest month $\left({ }^{\circ} \mathrm{C}\right)$.

\subsection{Data collection}

Forty trees per population were measured in each site (32 for Malcata site) $10 \mathrm{y}$ after plantation. Depending on the number of replicates in the site, 4-20 trees taken from the central part of the plot, to avoid border and competition effects among different populations, were measured for total height, diameter at breast height $(\mathrm{DBH})$ and stem form. Total height $( \pm 0.10 \mathrm{~m})$ was evaluated using a hypsometer (Vertex) and the mean of three measurements was registered. Tree DBH $( \pm 0.5 \mathrm{~cm})$ was evaluated in the same trees using a caliper. Stem form was evaluated using a notation scale ranging from 1 (crooked stem) to 6 (straight stem). Survival rate was evaluated as the percentage of surviving trees in each plot. This study counts a variable number of observations and missing values, depending on the site or trait considered.

\subsection{Data analysis}

Data analysis was based on individual observations for total height, DBH and stem form (Codesido and Fernández-López, 2008). In order to achieve normality, survival rate was subjected to the angular transformation of the surviving trees $(p)$ in a plot, $y=\arcsin \sqrt{p / 100}$.

The RCB design aims at separating environmental from genetic variance, assuming environmental homogeneity within each replicate. Within the large replicates $(0.5 \mathrm{ha})$ of the present trial, environmental heterogeneity was evident from direct field observations. A spatial analysis could not be performed, since the coordinates of each tree were not known. To test for such heterogeneity, in a first step random population, replicate and their interaction effects were included in singlesite analyses. With few exceptions, the variance estimates for the population $\times$ replicate interaction were larger and significant, indicating spatial heterogeneity.

To circumvent this problem, a new incomplete block (iBlock) design was superposed to the existing replicates. Under closed canopy, variable microenvironmental conditions are more accurately reflected by tree diameter (Tognetti et al., 2000), which provided a basis for the sub-partition in iBlocks. Mean DBH values for each population within replicate were represented by a colour scale that was superposed to the original design; the iBlocks' limits were then manually designed, gathering at least 3 contiguous populations, adjusting the limits to the colour pattern and to direct observation of the field conditions. The sub-partition resulted in a variable number of iBlocks within replicates in each site. To test for the efficacy of this post blocking procedure, model fitting was evaluated by means of the Akaike's Information criterion (Tab. II). 
Table II. Comparison of candidate multi-environment data models for statistical analyses, for all analysed traits (survival subjected to angular transformation). In these variance-component models, site is a fixed effect. The predictive quality of the models was evaluated by means of their AIC (Akaike's Information criterion) in the smaller-is-better form.

\begin{tabular}{|c|c|c|c|c|c|c|}
\hline & & & \multicolumn{4}{|c|}{ AIC } \\
\hline Model & Description & $\begin{array}{c}\text { No. of } \\
\text { covariance } \\
\text { parameters }\end{array}$ & $\begin{array}{c}\text { Total } \\
\text { height }\end{array}$ & $\mathrm{DBH}$ & $\begin{array}{l}\text { Stem } \\
\text { form }\end{array}$ & Survival \\
\hline 1 & $\begin{array}{l}\text { Uniform across-site population } \times \text { site } \\
\text { variance, site } \times \text { replicate variance and } \\
\text { residual variance. }\end{array}$ & 3 & 17823.4 & 28037.9 & 1579.1 & -4527.2 \\
\hline 2 & $\begin{array}{l}\text { The same model as in } 1 \text {, replacing site } \times \\
\text { replicate by the nested effect site } \times \\
\text { iBlock within replicate. }\end{array}$ & 3 & 16532.1 & 27175.8 & 1569.0 & -5737.9 \\
\hline 3 & $\begin{array}{l}\text { Heterogeneous across-site population } \\
\text { variances (5), iBlock within replicate } \\
\text { variances (5) and residual variances (5). }\end{array}$ & 15 & 16424.7 & 27042.5 & 1544.2 & -6269.0 \\
\hline
\end{tabular}

Linear mixed models based on REML methodology were used for statistical analyses, using SAS ${ }^{\odot}$ V9.1.3 (SAS Institute Inc., 1999) software. The selected models can be expressed by:

$$
y=X \beta+Z \gamma+\varepsilon
$$

where $y$ is the vector of observations; $X$ and $Z$ are design matrices of the parameters associated to fixed and random effects, respectively; $\beta$ and $\gamma$ are vectors of fixed and random effects, respectively; $\varepsilon$ is the vector of residual errors.

\subsubsection{Single-site analysis}

Single-site variance parameters were estimated analysing simultaneously the multi-environment (ME) data with a Variance Components (VC) model accommodating variance heterogeneity for the random effects: heterogeneous acrosssite population variances, iBlock within replicate variances and residual variances $(15 \mathrm{VC})$, modelling site as a fixed effect (Tab. II). Terms for replicate, or for the population $\times$ iBlock within replicate interaction were not included in the model since they lead either to the estimation of null or nonsignificant variance components, either to infinite likelihood.

Estimated variance components were used to derive population heritabilities $\left(H^{2}\right.$, representing a repeatability at the seedlot level), calculated for each trial as:

$$
H^{2}=\frac{\sigma_{\text {Pop }}^{2}}{\sigma_{\text {Pop }}^{2}+\frac{\sigma_{\text {illock(Rep) }}^{2}}{b}+\frac{\sigma_{c}^{2}}{n}}
$$

where $\sigma_{\text {Pop }}^{2}, \sigma_{\text {iBlock(Rep) }}^{2}$ and $\sigma_{\mathrm{e}}^{2}$ are the variance components for populations, iBlocks within replicates and residual errors, respectively; $b$ is the number of iBlocks (varying among sites); and $\mathrm{n}$ is the number of observations of each population in the site (varying among sites). The expected gain from selection of each population was estimated by $\left(\bar{X}_{\text {Pop }}-\bar{X}_{\text {general }}\right) H^{2}$, where $\bar{X}_{\text {Pop }}$ and $\bar{X}_{\text {general }}$ are the population and the general mean value for the trait in a given test site, respectively.
Single-site BLUP mean population values were estimated from single-site data analyses with a model accommodating $3 \mathrm{VC}$ for random effects: population, iBlock within replicate and residual variance. The only fixed effect was the overall mean.

\subsubsection{Across-site analysis}

Prior testing for significant GE interaction was based on a ME data model specifying site, population and site $\times$ population interaction as fixed effects, while accommodating heterogeneous across-site iBlock within replicate and residual variances (10 VC).

Mean comparisons among populations across sites were evaluated by contrasts of means at $\alpha=0.05$, comparing: all seedlots (30); Portuguese seedlots (22); seedlots from seed orchards (5) versus other populations (25); populations from 4 classes of altitude in Portugal [A (0-200 m), B (201-400 m), C (401-600 m), D (> $600 \mathrm{~m})$ ]; populations from different regions of provenance in Portugal (Tab. I). This analysis was based on a new ME data model specifying site and population as fixed effects, with the same $15 \mathrm{VC}$ structure described for model 3 (Tab. II).

\section{GGE biplot}

BLUP estimates of each population at each test site were displayed in a GGE biplot to visualize GE interaction patterns for total height among Portuguese seedlots. The 2-dimensional GGE biplot is based on the following model:

$$
y_{\mathrm{ij}}-e_{\mathrm{j}}=\xi_{\mathrm{i} 1} \lambda_{1} \eta_{\mathrm{j} 1}+\xi_{\mathrm{i} 2} \lambda_{2} \eta_{\mathrm{j} 2}+\varepsilon_{\mathrm{ij}}
$$

where $y_{\mathrm{ij}}$ is the BLUP value of population $i$ at test site $j, e_{\mathrm{j}}$ is the mean value of test site $j, \xi_{\mathrm{i} 1}$ and $\xi_{\mathrm{i} 2}$ are the eigenvectors of genotype $i$ on the first and the 2nd principal component (PC), respectively; $\eta_{\mathrm{j} 1}$ and $\eta_{\mathrm{j} 2}$ are the the eigenvectors of test site $j$ on the first and the 2 nd PC, respectively. $\lambda_{1}$ and $\lambda_{2}$ are the 
eigenvalues (singular values) of the first and 2 nd PC. $\varepsilon_{\mathrm{ij}}$ is the residual of population $i$ in test site $j$ that is not explained by the first two PC. To construct a biplot, the eigenvalues have to be partitioned into the population scores $\xi_{\mathrm{il}}^{*}$ and $\eta_{\mathrm{jl}}^{*}$ and the test site scores:

$$
\xi_{\mathrm{il}}^{*}=\xi_{\mathrm{il}} \lambda_{\mathrm{l}}^{f} \text { and } \eta_{\mathrm{j} 1}^{*}=\eta_{\mathrm{j} 1} \lambda_{\mathrm{l}}^{1-f},
$$

where $l$ can be 1 or 2 for the first and 2 nd PC, and $f$ is the singular value partition factor. On a 2-D GGE biplot, the populations and the test sites are displayed as single points defined by their PC1 scores against their PC2 sores. The biplot shape can be affected by the choice of $f$. It is called population-focused scaling if $f=1$ is used in constructing the biplot, which is suitable for population evaluation. It is called test site-focused scaling if $f=0$ is used in constructing the biplot, which is suitable for test site evaluation. It is called symmetrical scaling if $f=0.5$ is used in constructing the biplot, which is not ideal for either population evaluation or test site evaluation. The choice of $f$ value does not affect the biplot's ability to show the population by test site relationships (Yan, 2002).

The most important property of a biplot is its inner-product property. It is that the site-centered trait value of a population in a test site is graphically approximated by the product of the population vector, the test site vector, and the cosine of the angle between the two vectors (a vector is the distance between the biplot origin and the position of a population or test site). This property has two interesting applications in GGE biplot analysis. The first is the which-won-where view, and the second is the mean vs. stability view (Yan and Tinker 2006; Yan et al., 2007).

\section{The which-won-where view}

In this view of the GGE biplot, a polygon is first drawn on genotypes that are farthest from the biplot origin so that all other genotypes are contained within the polygon. Then lines perpendicular to each side of the polygon are drawn, starting from the biplot origin. These lines divide the biplot area into sectors and the test sites into groups. Each group of test sites has a corresponding winner population, which is the one located at the vertex of the polygon for the sector where the test sites are positioned. The which-won-where pattern is not affected by the singular value partitioning factor.

\section{The mean vs. stability view}

This view of a GGE biplot is formed by first defining an average test site, which is a point on the biplot that has the mean coordinates of all test sites. An average-environmentaxis (AEA) is then drawn, which passes through the biplot origin and the average test site. The interpretation is that the AEA represents the mean performance of the populations whereas the axis that is perpendicular to it represents the instability of the populations. This view is most meaningful when all the test sites are on the same side of the biplot origin along the AEA.

\section{RESULTS}

The comparison of candidate ME data models for statistical analyses showed that better fitted models were obtained using the post hoc blocking technique, agreeing with results obtained by Gezan et al. (2006), and considering heterogeneous variances across sites (Tab. II).

\subsection{Single-site analysis}

Significant population and iBlock within replicate variances were found for all traits in trial sites, with the exception of total height and DBH in Malcata and Montalegre; DBH in Viseu; stem form and survival in Montalegre (Tab. III). Heritabilities were not estimated when non-significant or null variances were detected. Population heritabilities, reflecting genetic contributions to the population variances, varied between $92 \%$ (Malcata) for survival and 56\% (Escaroupim) for DBH. Results suggest a more effective genetic control of growth and stem form in Escaroupim and of survival in high-altitude Malcata site. Heritabilities could not be estimated in Montalegre for any trait, due to non-significance of the environmental variance component.

The sites with higher growth were Viseu and Escaroupim (8.22 $\mathrm{m}$ and $7.05 \mathrm{~m}$ respectively, Supplementary material available online only at www.afs-journal.org, Tabs. SII-SVI). Mean total height was much lower in Malcata, Leiria and Montalegre ( $4.73 \mathrm{~m}, 4.58 \mathrm{~m}$ and $4.23 \mathrm{~m}$ respectively). In general, the Australian and Portuguese seed orchards and some Leiria or Monção populations displayed faster growth in the test sites. Some high altitude populations ranked higher in growth (Bragança, S.Pedro do Sul) or survival (ManteigasPma30) at $1000 \mathrm{~m}$ altitude (Montalegre site). Mediterranean Cuenca and Corsica were the slowest growing provenances, which can be interpreted as an adaptation to more xeric conditions of origin (Supplementary material available online only at www.afs-journal.org, Tab. SI). However, these latter populations, together with the Australian and Portuguese seed orchards, exhibited the best stem form. Our results confirm the superior form of the Corsican pine reported in other field studies (Alía et al., 1995; Hopkins and Butcher, 1993; Matziris, 1982).

The highest survival rate was found in Viseu (89\%) and the lowest in Escaroupim and Leiria (67\% e $68 \%$ respectively). The Leiria populations displayed high survival rates in some test sites but did not perform consistently across sites, the same instability being displayed by the Lousã populations and seed orchards.

\subsection{Across-site analysis}

GE interaction was significant for total height $(F=$ $\left.3.15^{* * *}\right), \mathrm{DBH}(F=1.78 * * *)$, stem form $(F=1.76 * * *)$ 
Table III. Single-site estimates of population, incomplete blocks within replicates and residual variances, and broad-sense heritabilities for total height $(\mathrm{m})$, diameter at breast height $(\mathrm{DBH}, \mathrm{cm})$, stem form (notation scale) and survival rate (subjected to angular transformation), based on multi-environment data analyses (Tab. II, model 3).

\begin{tabular}{|c|c|c|c|c|c|}
\hline & & \multicolumn{3}{|c|}{ Variance components estimates } & \multirow[b]{2}{*}{$\begin{array}{c}\text { Broad-sense } \\
\text { heritabilities }(\mathrm{H} 2)\end{array}$} \\
\hline & & Population & $\begin{array}{l}\text { Incomplete blocks } \\
\text { within replicates }\end{array}$ & Residual & \\
\hline \multirow[t]{4}{*}{ Escaroupim } & Total height & $0.37 * * *$ & $0.98 * * *$ & $1.25 * * *$ & 0.85 \\
\hline & $\mathrm{DBH}$ & $0.46 * *$ & $4.21 * * *$ & $8.29 * * *$ & 0.56 \\
\hline & Stem form & $0.058 * *$ & $0.047 * *$ & $0.713^{* * *}$ & 0.75 \\
\hline & Survival rate & $0.006 * * *$ & $0.022 * * *$ & $0.033^{* * *}$ & 0.78 \\
\hline \multirow[t]{4}{*}{ Leiria } & Total height & $0.14 * * *$ & $0.20 * * *$ & $0.96 * * *$ & 0.82 \\
\hline & DBH & $0.30 *$ & $1.01 * *$ & $7.05 * * *$ & 0.58 \\
\hline & Stem form & $0.048 * *$ & $0.039 *$ & $0.793 * * *$ & 0.69 \\
\hline & Survival rate & $0.006 * * *$ & $0.017 * * *$ & $0.014 * * *$ & 0.86 \\
\hline \multirow[t]{4}{*}{ Malcata } & Total height & $0.02^{\text {(n.s.) }}$ & $0.65 * * *$ & $0.85 * * *$ & (a) \\
\hline & $\mathrm{DBH}$ & 0.00 & $2.22 * * *$ & $4.55 * * *$ & (b) \\
\hline & Stem form & $0.072 * *$ & $0.098 * *$ & $1.038 * * *$ & 0.68 \\
\hline & Survival rate & $0.012 * * *$ & $0.016^{* * *}$ & $0.022 * * *$ & 0.92 \\
\hline \multirow[t]{4}{*}{ Montalegre } & Total height & $0.09^{* *}$ & $0.75^{\text {(n.s.) }}$ & $0.78 * * *$ & (a) \\
\hline & $\mathrm{DBH}$ & $0.27 * *$ & $3.56^{(\text {n.s. })}$ & $5.54 * * *$ & (a) \\
\hline & Stem form & $0.054 * *$ & $0.004^{(n . s)}$. & $1.128 * * *$ & (a) \\
\hline & Survival rate & $0.025 * * *$ & $0.011^{(n . s .)}$ & $0.010 * * *$ & (a) \\
\hline \multirow[t]{4}{*}{ Viseu } & Total height & $0.12 * * *$ & $0.44 * * *$ & $0.81 * * *$ & 0.78 \\
\hline & $\mathrm{DBH}$ & $0.03^{(\text {n.s. })}$ & $1.76 * * *$ & $5.48 * * *$ & (a) \\
\hline & Stem form & $0.045^{* *}$ & $0.055 * *$ & $0.984 * * *$ & 0.63 \\
\hline & Survival rate & $0.003 * * *$ & $0.008 * * *$ & $0.014 * * *$ & 0.83 \\
\hline
\end{tabular}

(a) Not estimated due to non-significance (n.s.) of one variance component.

(b) Not estimated due to null population variance.

and survival $(F=21.73 * * *)$. Across test sites, seed orchards displayed significantly better growth and stem form (total height, $F=47.08 * * *$; DBH, $F=13.80 * * *$; stem form, $F=55.33 * * *)$. Significant differentiation was found among the 30 seedlots for total height $(F=5.89 * * *)$ and stem form $(F=8.59 * * *)$, but among the 22 seedlots from Portugal only for stem form $(F=4.17 * * *)$. Among these 22 seedlots, stem form was significantly different among classes of altitude of origin $\left(F=6.6^{* * *}\right)$ and regions of provenance $(F=5.99 * * *)$, which could also be discriminated by total height $(F=2.36 *)$. No significant differentiation for survival was detected across sites (data not shown).

GE interaction patterns across the test sites for total height, in the subset of the 22 seedlots from Portugal, are represented in a biplot explaining $75.9 \%$ of the total $G+G E$ variation (Fig. 2A, 2B). Two sectors are visible in plot A: one includes test sites Escaroupim, Montalegre and Malcata, representing a mega-environment where the seed orchard (Pcse0102) material presents the best growth; the other includes Leiria and Viseu, where Pm33 performs the best. However, no common environmental pattern among the test sites within each macroenvironment is apparent ((Supplementary material available online only at www.afs-journal.org, Tab. SI). Escaroupim is the most discriminating (longest vector) and representative (smaller PC2 coordinate) test site, where differences among the genetic entries in total height can be more fully expressed. Malcata, however, is not suitable for total height evaluation (proximity to the biplot origin). The Viseu and Montalegre sites account for most of the growth GE interaction present (higher PC2 coordinates). Another graphic display of the same PC analysis (plot B) shows that the seed orchard (Pcse0102), 2 Monção (Pm33, Pm36) and 2 Leiria (Pmg46, Pmg52) populations were in average the faster growing, with Pm36 and Pmg52 displaying higher stability (lower $\mathrm{y}$-axis absolute projections). The biplot also shows that highaltitude populations Macedo de Cavaleiros (Pmc43) and Montalegre (Pmt40) were among the slowest growing (lower negative $x$-axis projections), and that populations from the same provenance region (e.g. the 3 Lousã populations P120, P124, $\mathrm{P} 126)$ had heterogeneous responses across sites.

\section{DISCUSSION}

\subsection{Growth, form and survival in the provenance test}

Broad sense heritabilities indicate moderate to high genetic control for analyzed traits, suggesting that phenotypic selection for these traits among populations is effective. The lack of significance of the environmental variance component in Montalegre for all traits may be due to the lower number of 

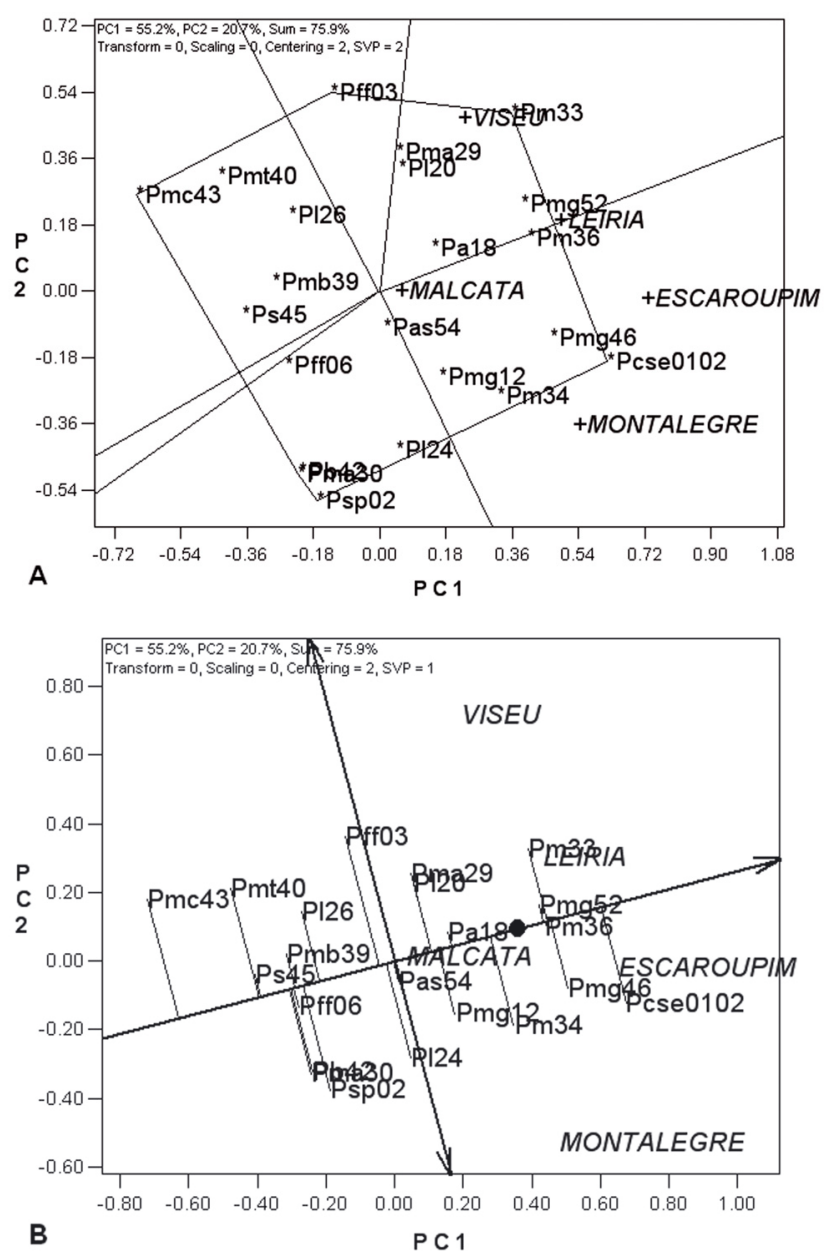

Figure 2. Genotype $\times$ Environment patterns for total height in the subset of 22 seedlots from Portugal. Plot A: identification of populations with the highest growth regarding the mega-environments (which-won-where view); Plot B: visualization of the mean performance and stability of the populations (mean vs. stability view). PC1 and PC2 = principal components 1 and 2, respectively; SVP, singularvalue partitioning.

replicates in this site and thus to a lower efficiency in capturing the environmental variance.

The higher growth displayed in Viseu and Escaroupim is linked to site characteristics (Tab. SI). These are sheltered test sites with deep soils, while Malcata and Montalegre are highaltitude sites with thinner soils and open wind-exposure. The slow growth observed in Leiria, a low-altitude site located in traditional pine areas, may be related to the existence of a subsoil imperm layer.

Special environment conditions may account for the low survival detected in Escaroupim and Leiria sites, such as floodprone areas during the rainy season in Escaroupim (maritime pine is intolerant to flooding), or lack of precipitation at the moment of plantation, when seedlings are more sensible to water stress, likely in the case of the Leiria trial. Although populations did not differ significantly in survival across sites, significant differences were detected in preliminary single-site analyses, suggesting that differences in the populations' plastic response are linked to local variations (high levels of environmental and residual variation were detected, Tab. III), expressing adaptation to coarse-grained environments. Moreover, significant population variation for plasticity within test sites was found for most of the traits, in preliminary single-site tests for the population $\times$ environment interaction.

The better performance of the Australian and Portuguese seed orchards across test sites is a consequence of humanmediated selection for traits with high heritabilities, while the higher growth of the Leiria and Monção seedlots may be explained by a general adaptation strategy developed by these populations. These materials could be potentially useful to reduce negative impacts of climate change in pine areas. In contrast, the higher rank of some high altitude populations (originating from colder environments) at Montalegre trial, with the lowest annual mean temperature of the test sites, may be a consequence of specific adaptation to this environment (Tab. I, Supplementary material available online only at www. afs-journal.org, Tab. SI).

Stem form differences among seed sources from Portugal were linked to their altitude class of origin and region of provenance; however we couldn't establish that high-altitude populations have straighter stems. Overall, a relationship of the analyzed traits with climatic variables or altitude at the population origin could not be reliably established in a preliminary correlation analysis at the individual population level. Only a few weak phenotypic correlations could be detected in single-site analyses, mostly with annual precipitation and mean minimal temperature of the coldest month (data not shown), indicating different trends of variation among populations originating from similar environments, for which no clear geographical pattern is apparent.

\subsection{GE interaction}

The GE interaction pattern found in our study may have several causes. (i) Differences in phenotypic plasticity among populations, representing an adaptive response to environmental heterogeneity resulting from biotic or abiotic factors. Phenotypic plasticity is under genetic control, has been reported in Maritime pine provenances (Chambel et al., 2007), and was present at the across and within-site level in our study. Population differences in phenotypic plasticity, associated to divergent trends in populations from similar environments, may explain the apparently non-congruent macroenvironments for total height (Fig. 2A). (ii) General adaptation, the strategy likely developed by the Leiria and Monção populations, able to maintain faster growth in diversified environments. (iii) Differential adaptation of populations with distinct origins, explaining the higher rank in growth or survival of some highaltitude populations at high-altitude test sites; or the generalized slower growth of the Mediterranean seed sources Corsica and Cuenca. (iv) Human intervention, which is determinant in the distribution of genetic resources. In the 20th century, nonidentified seed was used across Portugal, contributing to the 
lack of diversity structure reported by Ribeiro et al. (2001) using molecular markers, and rendering the true origin of some seed sources in the provenance trial uncertain. However, high density sowing that was used in the last century probably caused heavy competition, leading to survival of the fittest seedlings, and therefore to some degree of local adaptation to altitude. In these colder environments and under competitive pressure, natural selection acting after human sowing could explain the better ranking of some high-altitude populations at higher altitudes.

\subsection{Implications for afforestation, improvement and conservation}

Tentative recommendations are made for genetic resources from Portugal, but are expected to evolve as more information on other important traits, or on the impacts of climate changes, becomes available.

Qualified seed from the seed orchard (Pcse0102), and selected seed from Leiria and Monção (growth, form) and from Lousã (survival), can be used for general afforestation. Selected seed from high altitude populations Bragança, Manteigas (Pma30) and S.Pedro do Sul can be used in high altitude plantations. Altitude and ecological site conditions should be carefully considered when recommending genetic material for afforestation. For instance, Pmg 12 seed (Leiria) may lead to $37 \mathrm{~cm}$ gain in total height in sites similar to Escaroupim (Supplementary material available online only at www.afs-journal. org, Tab. S2) but to a loss of $11 \mathrm{~cm}$ in sites similar to Viseu. The obvious lack of genetic uniformity within provenance regions strongly advises a careful selection of specific seed sources within a provenance region for specific plantation conditions.

Our results reinforce the importance of establishing improved seed orchards in Leiria, Monção and Lousã with genetic material selected in the same region, which could lead to considerable gains in growth and form (presently up to $50 \mathrm{~cm}$ for Pcse0102 qualified seed), ensuring high levels of genetic diversity. Establishment of a seed orchard in altitude could be envisaged for high-altitude genetic material. Results also justify the attention that has been given to Leiria in breeding programs and suggest that Monção is also suitable for more intensive improvement actions.

Present results are in agreement with an earlier evaluation of this provenance trial, at 4 years from plantation (Aguiar et al., 1999). Leiria's vigour has been documented in several provenance trials (Alía et al., 1995 in Spain; Danjon, 1994 in south-western France; Hopkins and Butcher, 1993 in Australia; Matziris, 1982 in Greece). Leiria is one of the oldest pine areas in Portugal, planted in the 13th century for dune fixation and to provide wood for ship construction, where the traditional preservation of the plus trees for seed supply may have accounted for the good growth and form traits of this provenance. In this study Monção proved to be an equally vigorous provenance and a promising material for improvement. The better growth and stem form displayed by the Australian and Portuguese seed orchards (with Leiria present in their genetic basis) demonstrates the advantage of using improved seed for plantations. The high vigour of Atlantic populations is related to their adaptation to subhumid climates, but survival decreases under severe frost or water stress conditions. Given the survival pattern found in this study, we suggest that these factors should be carefully weighted when selecting genetic material for plantations.

Selection of in situ conservation areas in Leiria, Monção, and in altitude (for phenotypic superiority in growth and form and importance for improvement programs) is recommended. Dune protection populations in Leiria and ancient maritime pines habitats selected in the frame of Natura 2000 network should also be considered. Some improvement structures, such as the provenance test (for population's representation), seed orchard and clonal bank in Escaroupim (for valuable genetic resources), could be considered for ex situ conservation.

\section{CONCLUSIONS}

Significant differences between 30 maritime pine populations were found for growth and form, with seed orchards displaying significantly higher and straighter stems. Significant GE interaction was detected for all traits and revealed a pattern that could be explained by differences in phenotypic plasticity among populations, by general or differential adaptation of populations, and by human intervention in germplasm transfer.

Seed orchards (except Landps62) and Monção and Leiria populations showed generalized better growth and form, while some high altitude populations tended to rank higher at high altitude sites, suggesting that altitude may be an important factor to consider in the selection of genetic material. Populations from the same provenance region showed little uniformity, indicating that special care should be taken in selecting genetic material for plantations. Mediterranean Corsica and Cuenca performed distinctly, displaying superior stem form but reduced vigour. Overall, better performing populations (seed orchards, Monção and Leiria populations) can be used for general afforestation.

Acknowledgements: We are grateful to João Pessoa, Eugénia Rocha, Teresa Sampaio, André Viana, Fátima Carreira and Graça Andrade for assistance in field data collection; and to the Portuguese Forestry Services for field management of the provenance trial. We also thank Greg Dutkowski for sharing the ASReml approach to quantitative methods for tree breeding. This study was funded by INIAP/FCT project PARLE D, LT 4.

\section{REFERENCES}

Aguiar A., Roldão M.I., Esteves I. and Baeta J., 1999. Ensaio de Proveniências de Pinus pinaster Ait. Resultados de quatro anos de ensaio. Silva Lusitana 7: 39-47.

Alia R. and Martín S., 2003. EUFORGEN Technical Guidelines for genetic conservation and use for Maritime pine (Pinus pinaster). International Plant Genetic Resources Institute, Rome, Italy.

Alia R., Gil L. and Pardos J.A., 1995. Performance of 43 Pinus pinaster Ait. Provenances on 5 Locations in Central Spain. Silvae Genet 44: $75-81$. 
Alia R., Moro J. and Denis J.B., 1997. Performance of Pinus pinaster provenances in Spain: interpretation of the genotype by environment interaction. Can. J. For. Res. 27: 1548-1559.

Chambel M.R., Climent J. and Alía, R., 2007. Divergence among species and populations of Mediterranean pines in biomass allocation of seedlings grown under two watering regimes. Ann. For. Sci. 64: 87-97.

Codesido V. and Fernández-López J., 2008. Juvenile genetic parameters estimates for vigour, stem form, branching habit and survival in three Pinus radiata D. Don progeny tests in Galicia, Spain. Eur. J. For. Sci. 127: 315-325.

Costa e Silva J. and Potts B.M., 2006. Genotype by environment interaction for growth of Eucalyptus globulus in Australia. Tree Genet. Genomes 2: 61-75.

Crossa J., 1990. Statistical analysis of multilocation trials. Adv. Agron. 44: $55-85$.

Danjon F., 1994. Stand Features and Height Growth in a 36-Year-Old Maritime Pine (Pinus pinaster Ait.) Provenance Test. Silvae Genet. 43: 52-62.

Destremeau D.X., Jolly H. and Thari T., 1976. Contribution à la connaissance des provenances de Pinus pinaster. Ann. Rech. For. Maroc 16: 101-153.

Eveno E., Collada C., Guevara M.A., Léger V., Soto A., Díaz L., Léger P., González-Martínez S.C., Cervera M.T., Plomion C. and GarnierGéré P.H., 2008. Contrasting patterns of selection at Pinus pinaster Ait. Drought stress candidate genes as revealed by genetic differentiation analyses. Mol. Biol. Evol. 25: 417-437.

Fernandes L., Rocheta M., Cordeiro J., Pereira S., Gerber S., Oliveira M.M. and Ribeiro M.M., 2008. Genetic variation, mating patterns and gene flow in a Pinus pinaster Aiton clonal seed orchard. Ann. For. Sci. 65: 706.

Gabriel K.R., 1971. The biplot graphic display of matrices with application to principal component analysis. Biometrika 58: 453-467.

Gezan S.A., Huber D.A. and White T.L., 2006. Post hoc blocking to improve heritability and precision of best linear unbiased genetic predictions. Can. J. For. Res. 36: 2141-2147.

González-Martínez S.C., Alía R. and Gil L., 2002. Population genetic structure in a Mediterranean pine (Pinus pinaster Ait.): a comparison of allozyme markers and quantitative traits. Heredity 89: 199-206.

González-Martinez S.C., Mariette S., Ribeiro M.M., Burban C., Raffin A., Chambel M.R., Ribeiro C.A.M., Aguiar A., Plomion C., Alia R., Gil L., Vendramin G.G. and Kremer A., 2004. Genetic resources in maritime pine (Pinus pinaster Aiton): molecular and quantitative measures of genetic variation and differentiation among maternal lineages. For. Ecol. Manage. 197: 103-115.
Guyon J.P. and Kremer A., 1982. Phenotypic stability of height growth, daily changes in sap pressure and transpiration in maritime pine (Pinus pinaster Ait.). Can. J. For. Res. 12: 936-946.

Hopkins E.R. and Butcher T.B., 1993. Provenance comparisons of Pinus pinaster Ait. in Western Australia. CalmScience 1: 55-105.

Matziris D.I., 1982. Variation in growth and quality characters in Pinus pinaster provenances grown at seven sites in Greece. Silvae Genet. 31: 168-173.

Nguyen-Queyrens A., Loustau D., Ferhi A. and Guehl J.M., 1998. Within-ring $\delta^{13} \mathrm{C}$ spatial variability and interannual variations in wood cellulose of two contrasting provenances of Pinus pinaster. Can. J. For. Res. 28: 766-773.

Piepho H.P., Mohring J., Melchinger A.E. and Buchse A., 2008. BLUP for phenotypic selection in plant breeding and variety testing, Euphytica 161, 209-228.

Ribeiro M.M., Plomion C., Petit R., Vendramin G.G. and Szmidt A.E., 2001. Variation of chloroplast simple-sequence repeats in Portuguese maritime pine (Pinus pinaster Ait.). Theor. App. Genet. 102: 97-103.

Sierra de Grado R., Moulia B., Fournier M., Alía R., Díez-Barra R., 1997. Genetic control of stem form in Pinus pinaster Ait. seedlings exposed to lateral light. Trees-Struct Funct 11: 455-461.

Simsek Y., Tulukcu M. and Toplu F., 1985. Studies on the variation in growth and quality characteristics of Pinus pinaster (Ait.) provenance trials in Turkey. Ormancilik Arastirma Enstitusu Yayinlari, Ankara, Teknik Bülten Serisi No. 149.

Tognetti R., Michelozzi M., Lauteri M., Brugnoli E. and Giannini R., 2000. Geographic variation in growth, carbon isotope discrimination, and monoterpene composition in Pinus pinaster Ait. provenances. Can. J. For. Res. 30: 1682-1690.

Yan W. and Tinker N.A., 2006. Biplot analysis of multi-environment trial data: principles and applications. Can. J. Plant. Sci. 86: 623-645.

Yan W., 2002. Singular-Value Partitioning in biplot analysis of multienvironment Trial Data. Agron. J. 94: 990-996.

Yan W., Hunt L.A., Sheng Q. and Szlavnics Z., 2000. Cultivar evaluation and mega-environment investigation based on the GGE Biplot. Crop. Sci. 40: 597-605.

Yan W., Kang M.S., Ma B., Woods S. and Cornelius P.L., 2007. GGE Biplot vs. AMMI Analysis of Genotype-by-Environment Data. Crop. Sci. 47: 641-653.

Zas R., Merlo E., Fernández-López J., 2004. Genotype x environment interaction in maritime pine families in Galicia, northwest Spain. Silvae Genet. 53: 175-182. 